\title{
Design and Evaluation of Photo-Induced Biofeedback Fabric for the Enhancement in Sleeping Sense
}

\author{
Wei-Cheng Chu, ${ }^{1}$ Hsin-Ju Lin, ${ }^{1}$ and Shu-Ping Chiu ${ }^{2}$ \\ ${ }^{1}$ Department of Fashion Design, Shu-Te University, No. 59, Hengshan Road, Yanchao District, Kaohsiung City 824, Taiwan \\ ${ }^{2}$ Graduate School of Design Doctoral Program, National Yunlin University of Science and Technology, No. 672, Demin Road, \\ Nanzi District, Kaohsiung City 811, Taiwan
}

Correspondence should be addressed to Wei-Cheng Chu; wjphilip@stu.edu.tw

Received 10 September 2013; Accepted 8 November 2013

Academic Editor: Shoou-Jinn Chang

Copyright (c) 2013 Wei-Cheng Chu et al. This is an open access article distributed under the Creative Commons Attribution License, which permits unrestricted use, distribution, and reproduction in any medium, provided the original work is properly cited.

\begin{abstract}
Based on overcoming the sleeping obstacle for people, the purpose of this study is to design a photo-induced biofeedback fabric which is a kind of optical fiber fabric with the function of enhancing sleeping sense and to evaluate its effect. The fabrics with two layers including background layer and pattern layer were designed firstly. The pattern layers with 3 kinds of wavelengths of sine waves and the light controller with 3 kinds of flashing frequencies were then prepared. Guiding the light into the optical fiber, it will emit out of the optical fiber and stimulate our visual system to change the form of brain wave. Finally, EEG and sleeping scale were applied to evaluate the effect of enhancing sleeping sense. The results were shown that human's brain wave can be changed from sober status to shallow-sleeping status and the effect of enhancing sleeping sense can be achieved for all pattern layers in frequencies of 0,5 and $10 \mathrm{~Hz}$. Furthermore, female is more significant than male and participants age from 30 to 49 are the most significant. Besides, the stronger the participant's stress is, the more significant the sleeping sense is.
\end{abstract}

\section{Introduction}

According to the investigation of Taiwan Society of Sleep Medicine (TSSM), more than 4.5 million people have sleeping obstacle and 2.5 million people have suffered from chronic insomnia in Taiwan in 2006. Only a few people would like to consult doctors for this general issue. Therefore, how to enhance sleeping sense by using an effective and natural method has become an important issue and needs to be studied. Because the sleeping quality is strongly relative to stress $[1,2]$, stress relaxation and providing sound sleeping quality are the main aims of this paper.

In general, methods of stress relaxation are listed as follow: medical control treatment, exercise and homework treatment, breathing control treatment, musical treatment, Biofeedback treatment, and so forth $[3,4]$. The principle of Biofeedback was adopted in this paper and was applied to train the people with sleeping obstacle to realize that it is their own ability to exercise self-control and self-adjustment, as well as it is also to make them understand that it is one's own responsibility to overcome this stress problem [5-7].
Referring to the aforesaid method of biofeedback treatment, a unique home decoration fabric with the functions of stress relaxation and sleeping sense enhancement was created by the combination of textile, photoelectric system, and medical technology. This is in a way with the hope to stimulate the activity of the brain wave by the light emitting out of the optical fibers which were weaved into fabric and sewn on it, other than by medication. It is expected that such innovation can release the stress exerted in our busy life and provide a new natural way choice of stress relaxation and enhancing sleeping sense for the people.

\section{Materials and Methods}

2.1. Biofeedback Fabrics Design. There are two layers in this biofeedback fabric including pattern layer and background layer. The background layer is woven with the warp and the weft densities of 36 ends per inch by 150 denier white synthetic filament yarn (SFY) and plastic optical fiber (POF) of $0.25 \mathrm{~mm}$ diameter. By sewing the Plastic Optical Fibers 


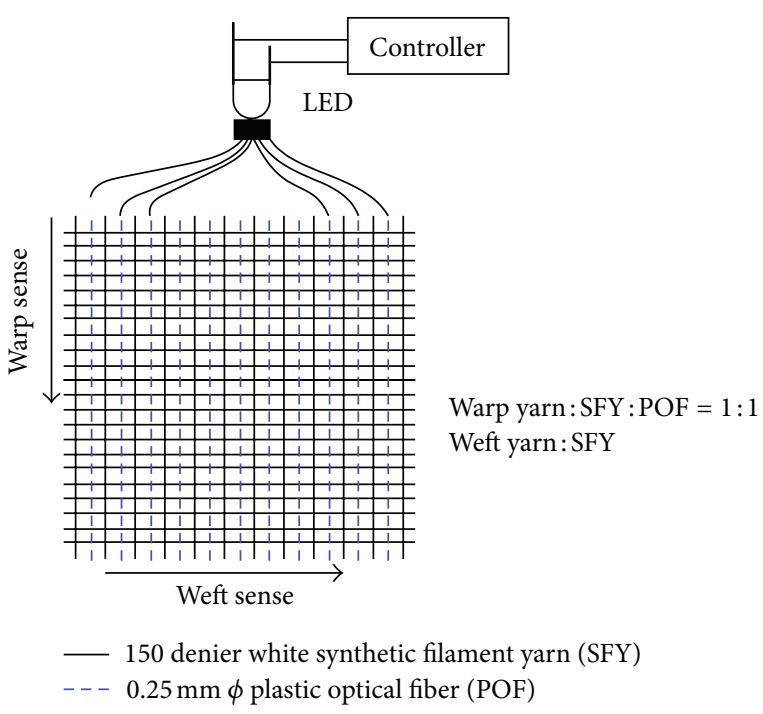

FIgURE 1: A design draft of background layer.

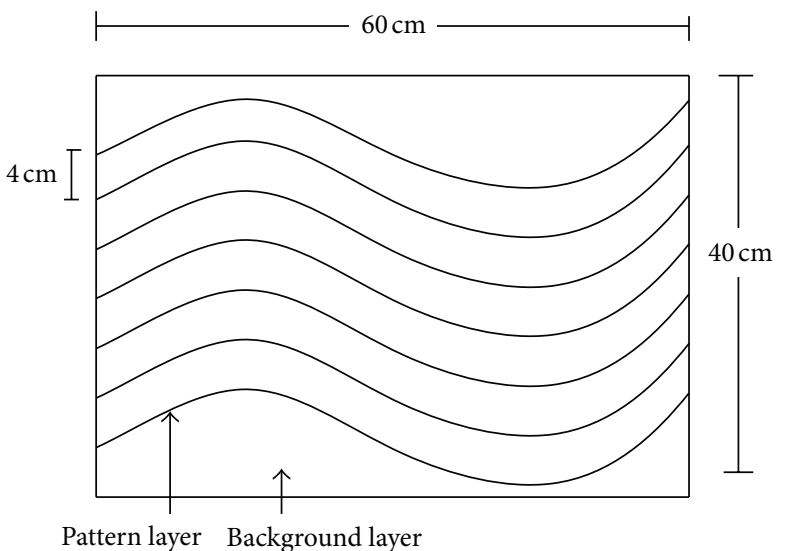

Figure 2: A design draft of pattern layer with $\lambda=60 \mathrm{~cm}$ sine wave.

(POFs) of $1.5 \mathrm{~mm}$ diameter on the surface of the background layer in a form of sine wave with various wavelengths as the pattern layer, the light can be guided into one end of the POFs and then emit out of the lateral of the POFs. The emitting light can stimulate a change of the brain wave by the reaction of man's visual system. Besides, a light controller was designed for obtaining various flashing frequencies of light. The details of the design for our study were described as follows.

(1) Background Layer. The background layer draft was shown in Figure 1. A plain weave fabric was applied to this background layer. The warp yarn of the background layer is composed of synthetic filament yarn and plastic optical fiber (POF) in ratio of $1: 1$ for color appearance in background layer. The weft yarn is applied with the same SFY as the warp yarn. All of the POFs of the warp yarn were gathered into
TABLE 1: Analysis of differences of the participants' brain waves in phases of $f_{1}, f_{2}$, and $f_{3}$ at resumed stages for all samples by ANOVA test.

\begin{tabular}{|c|c|c|c|c|c|c|c|}
\hline Sample & $\begin{array}{l}\text { Brain } \\
\text { wave }\end{array}$ & & $f_{1}$ & $f_{2}$ & $f_{3}$ & $F$ & $P$ \\
\hline \multirow{8}{*}{ Sample 1} & $\mathrm{~B}_{1}$ & $\mathrm{M}$ & 4.99 & 5.19 & 4.76 & \multirow{2}{*}{.201} & \multirow{2}{*}{.818} \\
\hline & Alpha & SD & 2.20 & 2.73 & 2.94 & & \\
\hline & $\mathrm{B}_{2}$ & $\mathrm{M}$ & 3.90 & 4.14 & 3.89 & \multirow{2}{*}{.310} & \multirow{2}{*}{.734} \\
\hline & Beta & SD & 1.36 & 1.31 & 1.46 & & \\
\hline & $\mathrm{B}_{3}$ & $\mathrm{M}$ & 3.52 & 3.69 & 3.29 & \multirow{2}{*}{.498} & \multirow{2}{*}{.610} \\
\hline & Theta & SD & 1.42 & 1.64 & 1.64 & & \\
\hline & $\mathrm{B}_{4}$ & $\mathrm{M}$ & 6.36 & 7.37 & 6.21 & \multirow{2}{*}{.824} & \multirow{2}{*}{.442} \\
\hline & Delta & SD & 3.50 & 4.23 & 3.69 & & \\
\hline \multirow{8}{*}{ Sample 2} & $\mathrm{~B}_{1}$ & M & 6.00 & 6.09 & 5.93 & \multirow{2}{*}{.035} & \multirow{2}{*}{.966} \\
\hline & Alpha & SD & 2.32 & 2.28 & 2.33 & & \\
\hline & $\mathrm{B}_{2}$ & M & 4.13 & 4.23 & 4.38 & \multirow{2}{*}{.458} & \multirow{2}{*}{.634} \\
\hline & Beta & $\mathrm{SD}$ & 0.86 & 1.01 & 1.15 & & \\
\hline & $\mathrm{B}_{3}$ & $\mathrm{M}$ & 4.08 & 4.30 & 4.16 & \multirow{2}{*}{.303} & \multirow{2}{*}{.739} \\
\hline & Theta & SD & 1.04 & 1.16 & 1.15 & & \\
\hline & $\mathrm{B}_{4}$ & $\mathrm{M}$ & 4.27 & 8.61 & 7.88 & \multirow{2}{*}{.820} & \multirow{2}{*}{.44} \\
\hline & Delta & SD & 3.19 & 4.98 & 4.27 & & \\
\hline \multirow{8}{*}{ Sample 3} & $\mathrm{~B}_{1}$ & $\mathrm{M}$ & 5.93 & 5.89 & 5.65 & \multirow{2}{*}{.128} & \multirow{2}{*}{.880} \\
\hline & Alpha & SD & 2.26 & 2.31 & 2.28 & & \\
\hline & $\mathrm{B}_{2}$ & $\mathrm{M}$ & 4.52 & 4.39 & 4.27 & \multirow{2}{*}{.395} & \multirow{2}{*}{.675} \\
\hline & Beta & SD & 1.02 & 1.10 & 1.08 & & \\
\hline & $\mathrm{B}_{3}$ & M & 4.29 & 4.30 & 4.49 & \multirow{2}{*}{.165} & \multirow{2}{*}{.848} \\
\hline & Theta & SD & 1.01 & 1.14 & 2.06 & & \\
\hline & $\mathrm{B}_{4}$ & $\mathrm{M}$ & 6.89 & 7.76 & 7.79 & \multirow{2}{*}{.931} & \multirow{2}{*}{.398} \\
\hline & Delta & SD & 2.62 & 3.50 & 2.51 & & \\
\hline
\end{tabular}

a strand and connected to a 0.3 watt natural LED light with a flashing frequency adjusted by a light controller.

(2) Pattern Layer. The pattern layer draft was shown in Figure 2. For the curvature of pattern layer, plural sine waves with wavelengths $(\lambda)$ of $60 \mathrm{~cm}$ in sample $1\left(S_{1}\right), 30 \mathrm{~cm}$ in sample $2\left(S_{2}\right)$, and $10 \mathrm{~cm}$ in sample $3\left(S_{3}\right)$ in a ratio of amplitude to wavelength $1: 2$, were arranged horizontally with a distance of $4 \mathrm{~cm}$ between each line. The plastic optical fibers of $1.5 \mathrm{~mm}$ diameter with significant side emitting light characteristic were sewn on the background layer with transparent Polyamide 6 filament yarns of $0.2 \mathrm{~mm}$ diameter. All of the POFs of pattern layer were gathered into a strand and connected to a 0.3 watt blue LED light with a flashing frequency adjusted by a light controller.

(3) Light Controller. There are four types of light intensities and were provided including dark, glimpse, moderate, and strong. Besides, three types of the flashing frequencies were provided including $0 \mathrm{HZ}\left(f_{1}\right), 5 \mathrm{HZ}\left(f_{2}\right)$, and $10 \mathrm{HZ}\left(f_{3}\right)$. The LED can be connected with the strand of POFs by using a black thermoplastic tube. 
TABLE 2: Analysis of brain wave differences between resumed stage (RS) and stimulated stage (SS) in phases of $f_{1}, f_{2}$, and $f_{3}$ for all samples by $t$-test.

\begin{tabular}{|c|c|c|c|c|c|c|c|c|c|c|c|c|c|c|c|c|c|c|}
\hline \multirow[t]{2}{*}{ Sample } & \multicolumn{2}{|c|}{$f_{1}$} & \multirow{3}{*}{$\begin{array}{c}\mathrm{M} \\
4.99 \\
3.68\end{array}$} & \multirow{2}{*}{$\frac{S D}{2.80}$} & \multirow{3}{*}{$\frac{t}{2.637}$} & \multirow{3}{*}{$\begin{array}{c}P \\
.110\end{array}$} & \multicolumn{2}{|c|}{$f_{2}$} & \multirow{3}{*}{$\begin{array}{c}\mathrm{M} \\
5.19 \\
3.56\end{array}$} & \multirow{3}{*}{$\begin{array}{c}\text { SD } \\
2.73 \\
1.50\end{array}$} & \multirow{3}{*}{$\frac{t}{2.853}$} & \multirow{3}{*}{$\begin{array}{c}P \\
.007\end{array}$} & \multicolumn{2}{|c|}{$f_{3}$} & \multirow{3}{*}{$\begin{array}{c}\mathrm{M} \\
4.76 \\
3.41\end{array}$} & \multirow{3}{*}{$\begin{array}{c}\text { SD } \\
2.94 \\
1.71\end{array}$} & \multirow{3}{*}{$\begin{array}{c}t \\
2.175\end{array}$} & \multirow{3}{*}{$\begin{array}{c}P \\
.035\end{array}$} \\
\hline & B & RS & & & & & $B$ & RS & & & & & & RS & & & & \\
\hline & $D_{1}$ & SS & & 1.59 & & & & SS & & & & & & SS & & & & \\
\hline \multirow{6}{*}{ Sample 1} & $\mathrm{~B}_{2}$ & RS & 3.90 & 1.36 & \multirow{2}{*}{-3.37} & \multirow{2}{*}{.737} & \multirow{2}{*}{$\mathrm{B}_{2}$} & RS & 4.14 & 1.31 & \multirow{2}{*}{.520} & \multirow{2}{*}{.605} & \multirow{2}{*}{$\mathrm{B}_{2}$} & RS & 3.98 & 1.45 & \multirow{2}{*}{-4.520} & \multirow{2}{*}{.653} \\
\hline & $D_{2}$ & SS & 4.03 & 1.52 & & & & SS & 3.95 & 1.41 & & & & SS & 4.06 & 1.47 & & \\
\hline & \multirow{2}{*}{$\mathrm{B}_{3}$} & RS & 3.52 & 1.42 & \multirow{2}{*}{-3.189} & 003 & $\mathrm{~B}_{2}$ & RS & 3.69 & 1.64 & -2502 & 015 & $B_{1}$ & RS & 3.29 & 1.64 & & .008 \\
\hline & & SS & 5.30 & 2.69 & & .000 & $\mathrm{O}_{3}$ & SS & 4.92 & 2.13 & 2.502 & . & $\mathrm{D}_{3}$ & SS & 4.67 & 2.18 & & .000 \\
\hline & & RS & 6.36 & 3.50 & & 000 & & RS & 7.37 & 4.23 & & 00 & & RS & 6.21 & 3.69 & & 000 \\
\hline & $\mathrm{D}_{4}$ & SS & 14.11 & 8.40 & & .000 & & SS & 12.68 & 6.30 & & .000 & & SS & 11.58 & 6.37 & & .000 \\
\hline & B. & RS & 6.00 & 2.32 & & 000 & & RS & 6.09 & 2.28 & & 00 & & RS & 5.93 & 2.33 & & 00 \\
\hline & $\mathbf{D}_{1}$ & SS & 4.12 & 1.06 & & .000 & & SS & 3.97 & .99 & & .000 & & SS & 3.91 & .97 & & .000 \\
\hline & $\mathrm{B}_{2}$ & RS & 4.13 & .86 & & .219 & $\mathrm{~B}_{2}$ & RS & 4.23 & 1.01 & & $9^{5} \quad$ & & RS & 4.38 & 1.15 & & 708 \\
\hline Sample 2 & $\mathrm{~N}_{2}$ & SS & 4.47 & 1.23 & & & $\mathbf{D}_{2}$ & SS & 4.25 & 1.02 & & הכני & 2 & SS & 4.26 & 1.26 & & .700 \\
\hline & $\mathrm{B}$ & RS & 4.08 & 1.04 & & 001 & $B_{2}$ & RS & 4.30 & 1.16 & & .008 & & RS & 4.16 & 1.14 & & .000 \\
\hline & $\omega_{3}$ & SS & 5.64 & 2.20 & & .001 & 3 & SS & 5.47 & 1.99 & & .000 & & SS & 5.79 & 2.05 & & \\
\hline & & RS & 7.21 & 3.19 & & 000 & & RS & 8.61 & 4.98 & & $00_{-}$ & & RS & 7.88 & 4.27 & & 000 \\
\hline & $\mathrm{B}_{4}$ & SS & 15.01 & 7.28 & & .000 & $\mathrm{~B}_{4}$ & SS & 14.45 & 6.91 & & .000 & -4 & SS & 14.80 & 6.62 & & .000 \\
\hline & & RS & 5.93 & 2.26 & & 669 & & RS & 5.89 & 2.31 & & 00 & & RS & 5.65 & 2.28 & & 000 \\
\hline & $\mathbf{D}_{1}$ & SS & 5.33 & 2.30 & & & & SS & 3.95 & 1.09 & & .000 & & SS & 3.82 & 1.34 & & .000 \\
\hline & $B_{2}$ & RS & 4.52 & 1.02 & 830 & 410 & & RS & 4.39 & 1.10 & 35 & 89 & & RS & 4.27 & 1.08 & & 932 \\
\hline Sam & $\mathrm{D}_{2}$ & SS & 4.29 & 1.08 & .030 & .410 & $\mathbf{D}_{2}$ & SS & 4.35 & 1.16 & ה & (1) & $\nu_{2}$ & SS & 4.25 & 1.26 & .005 & .952 \\
\hline & & RS & 4.29 & 1.01 & & & & RS & 4.30 & 1.14 & & & & RS & 4.49 & 2.06 & & \\
\hline & $\mathrm{B}_{3}$ & SS & 5.65 & 2.07 & & .003 & $\mathrm{~B}_{3}$ & SS & 5.64 & 2.31 & & .007 & 3 & SS & 5.33 & 2.34 & & .144 \\
\hline & B & RS & 6.89 & 2.62 & & 000 & & RS & 7.76 & 3.50 & & 00 & & RS & 7.79 & 2.51 & & \\
\hline & $\mathbf{D}_{4}$ & SS & 14.87 & 8.26 & 4.097 & & $\mathrm{D}_{4}$ & SS & 14.69 & 8.26 & & & & SS & 12.77 & 6.86 & & \\
\hline
\end{tabular}

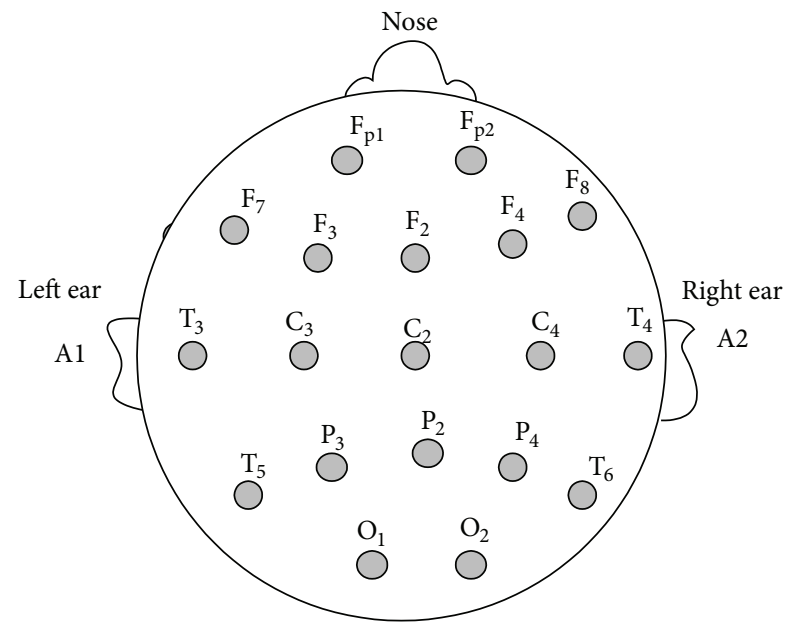

FIGURE 3: Brain wave potential position.

\subsection{Evaluating Procedure and Method}

(1) Biofeedback Apparatus for Measuring Brain Wave. This experiment used PED international Limited Electroencephalogram (EEG) measurement instrument model no: 1$330 \mathrm{C}-2, \mathrm{~J}+\mathrm{J}$ engineering as the main equipment to measure and collect data. This instrument is equipped with Physiolab USE3'S Software for data storing and data analyzing.

This experiment sets the brain wave into 4 categories as follows:

(1) $B_{1}$ is Alpha wave ranged from 8 to $14 \mathrm{HZ}$;

(2) $B_{2}$ is Beta wave ranged from 14 to $40 \mathrm{HZ}$;

(3) $\mathrm{B}_{3}$ is Theta wave ranged from 4 to $8 \mathrm{HZ}$;

(4) $\mathrm{B}_{4}$ is Delta wave ranged from 0.4 to $4 \mathrm{HZ}$.

The brain wave electrodes are located in $\mathrm{F} 8$ as positive, A2 as negative behind the right ear, and $\mathrm{A} 1$ as ground behind the left ear as shown in Figure 3. The biofeedback reaction will go into the encoder unit via the above said EEG measurement instrument. The brain wave reaction of the participant will simultaneously indicate on the computer screen.

(2) Sleeping Scale. We widely collected 130 adjectives related to sleeping sense and relaxation from the literature. The 21 preferable adjectives were selected by using KJ (Kawakita Jiro) method which is a grouping method performed by 6 members. Finally, 7 adjectives were chosen including Relaxed (Q1), Soft (Q2), Comfortable (Q3), Stretchable (Q4), Light (Q5), Free (Q6), and Sleepy (Q7); those 21 adjectives by using SDT (Semantic Differential Technique) of 5 scales performed by 30 subjects. After transferring these 7 adjectives into 7 questions and a sleeping scale of SDT with 11 scales (0 to 10), 
TABLE 3: Analysis of brain wave differences among $f_{1}, f_{2}$, and $f_{3}$ for all samples at stimulated stage by ANOVA test.

\begin{tabular}{|c|c|c|c|c|c|c|c|}
\hline Sample & $\begin{array}{l}\text { Brain } \\
\text { wave }\end{array}$ & & $f_{1}$ & $f_{2}$ & $f_{3}$ & $F$ & $P$ \\
\hline \multirow{8}{*}{ Sample 1} & $\mathrm{~B}_{1}$ & $\mathrm{M}$ & 3.68 & 3.56 & 3.41 & \multirow{2}{*}{.224} & \multirow{2}{*}{.799} \\
\hline & Alpha & SD & 1.59 & 1.50 & 1.71 & & \\
\hline & $\mathrm{B}_{2}$ & $\mathrm{M}$ & 4.03 & 3.96 & 4.06 & \multirow{2}{*}{.041} & \multirow{2}{*}{.960} \\
\hline & Beta & SD & 1.52 & 1.41 & 1.47 & & \\
\hline & $\mathrm{B}_{3}$ & $\mathrm{M}$ & 5.30 & 4.92 & 4.67 & \multirow{2}{*}{.537} & \multirow{2}{*}{.587} \\
\hline & Theta & SD & 2.69 & 2.13 & 2.18 & & \\
\hline & $\mathrm{B}_{4}$ & $\mathrm{M}$ & 14.11 & 12.68 & 11.58 & \multirow{2}{*}{.962} & \multirow{2}{*}{.386} \\
\hline & Delta & SD & 8.40 & 6.30 & 6.37 & & \\
\hline \multirow{8}{*}{ Sample 2} & $\mathrm{~B}_{1}$ & $\mathrm{M}$ & 4.12 & 3.97 & 3.91 & \multirow{2}{*}{.316} & \multirow{2}{*}{.730} \\
\hline & Alpha & SD & 1.06 & .99 & .97 & & \\
\hline & $\mathrm{B}_{2}$ & $\mathrm{M}$ & 4.47 & 4.25 & 4.26 & \multirow{2}{*}{.333} & \multirow{2}{*}{.717} \\
\hline & Beta & SD & 1.23 & 1.02 & 1.26 & & \\
\hline & $\mathrm{B}_{3}$ & $\mathrm{M}$ & 5.64 & 5.47 & 5.79 & \multirow{2}{*}{.178} & \multirow{2}{*}{.838} \\
\hline & Theta & SD & 2.20 & 1.99 & 2.05 & & \\
\hline & $\mathrm{B}_{4}$ & $\mathrm{M}$ & 15.04 & 14.45 & 14.80 & \multirow{2}{*}{.050} & \multirow{2}{*}{.951} \\
\hline & Delta & SD & 7.28 & 6.91 & 6.62 & & \\
\hline \multirow{8}{*}{ Sample 3} & $\mathrm{~B}_{1}$ & $\mathrm{M}$ & 5.33 & 3.95 & 3.82 & \multirow[t]{2}{*}{1.117} & \multirow[t]{2}{*}{.332} \\
\hline & Alpha & SD & 1.30 & 1.09 & 1.34 & & \\
\hline & $\mathrm{B}_{2}$ & $\mathrm{M}$ & 4.29 & 4.35 & 4.25 & \multirow{2}{*}{.058} & \multirow{2}{*}{.944} \\
\hline & Beta & SD & 1.08 & 1.16 & 1.26 & & \\
\hline & $\mathrm{B}_{3}$ & $\mathrm{M}$ & 5.65 & 5.64 & 5.33 & \multirow{2}{*}{.191} & \multirow{2}{*}{.827} \\
\hline & Theta & SD & 2.07 & 2.31 & 2.35 & & \\
\hline & $\mathrm{B}_{4}$ & $\mathrm{M}$ & 14.87 & 14.69 & 12.77 & \multirow{2}{*}{.653} & \multirow{2}{*}{.523} \\
\hline & Delta & SD & 8.53 & 8.26 & 6.86 & & \\
\hline
\end{tabular}

they were utilized to evaluate the sleeping sense in this study. For further data analysis, the 6 questions of Q1 to Q6 can be grouped together standing for Relaxed as Q1-Q6 expressed in Table 9 to Table 12 .

(3) Evaluating Procedure. The evaluating procedure of this experiment was shown in Figure 4 and described below.

(1) 5 minutes before the evaluation is conducted, the participants have to be informed of the purpose and the procedure in preparation stage and the samples should be prepared as showed in Figure 5.

(2) For the comparison of sleeping sense after the stimulated stage, filling sleeping scale is conducted in 1 minute before starting the resumed stage.

(3) Closing the eyes and taking a rest for 3 minutes is necessary in resumed stage (RS), it can assure that the participant's condition has recovered from the former evaluated stage (SS).

(4) In the stimulated stage (SS), the participants open their eyes and look at the biofeedback fabric for 3 minutes. During this period of time, the participants' visual system will be stimulated and their brain waves

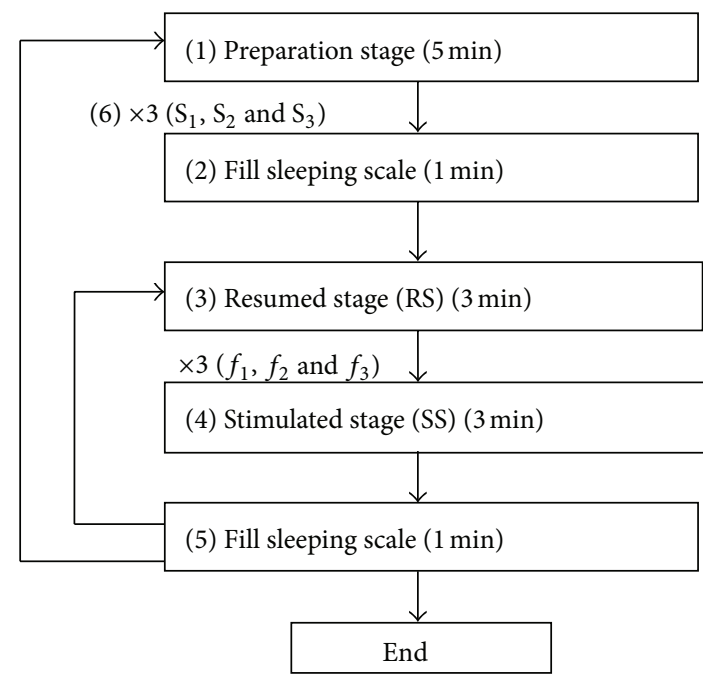

FIgURE 4: A flow chart of the evaluating procedure with EEG instrument and sleeping scale.

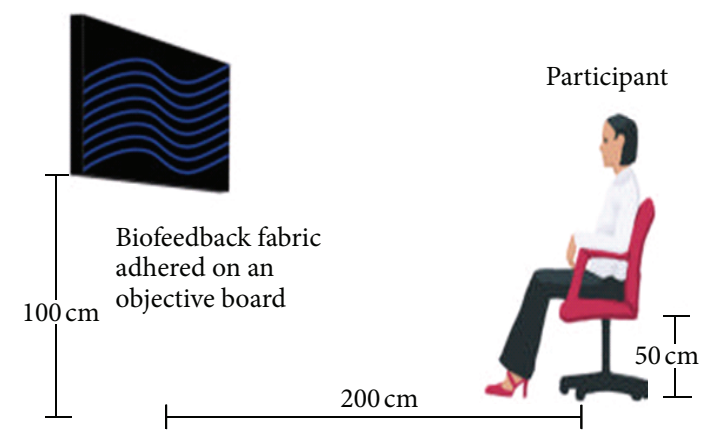

FIgURE 5: An illustration of the relative position in evaluation room.

was changed and then recorded at every 10 -seconds interval.

(5) Filling sleeping scale in 1 minute after each stimulated stage for the comparison of sleeping sense and repeating (3) to (5) steps for 3 types of the flashing frequencies $\left(f_{1}, f_{2}\right.$, and $\left.f_{3}\right)$ of the biofeedback fabric are done, and then the experiment is completed for every single sample.

(6) Repeating (2) to (5) steps for all the 3 samples of the different curvatures $\left(S_{1}, S_{2}\right.$, and $\left.S_{3}\right)$ of biofeedback fabric are done, and then the experiment is completed for single subject.

(4) Evaluating Condition. Before the starting of this experiment, the relevant conditions and factors which may affect the result of the experiment should be kept constantly and remained throughout the whole experiment. The biofeedback fabric is placed at $100 \mathrm{~cm}$ above the ground level and the distance between the biofeedback fabric and participant is $200 \mathrm{~cm}$. The participant sits straight at eyes level with the objective board in horizontal level as shown in Figure 5. The light strength of the evaluating room is kept under $0.001 \mathrm{~lx}$. The participant should be motionless, keeping silence and 
TABLE 4: Analysis of female brain wave differences between resumed stage and stimulated stage in phases of $f_{1}, f_{2}$, and $f_{3}$ by $t$-test.

\begin{tabular}{|c|c|c|c|c|c|c|c|c|c|c|c|c|c|c|c|c|c|}
\hline & 1 & M & SD & $t$ & $P$ & \multicolumn{2}{|c|}{$f_{2}$} & M & SD & $t$ & $P$ & \multicolumn{2}{|c|}{$f_{3}$} & $\mathrm{M}$ & SD & $t$ & $P$ \\
\hline \multirow{2}{*}{$\mathrm{B}_{1}$} & RS & 4.841 & 1.899 & \multirow{2}{*}{2.544} & \multirow{2}{*}{.017} & \multirow{2}{*}{$\mathrm{B}_{1}$} & RS & 5.091 & 2.754 & \multirow{2}{*}{2.342} & \multirow{2}{*}{.031} & \multirow{2}{*}{$\mathrm{B}_{1}$} & RS & 4.773 & 2.601 & \multirow{2}{*}{1.944} & \multirow{2}{*}{.062} \\
\hline & SS & 3.320 & 1.324 & & & & SS & 3.293 & 1.119 & & & & SS & 3.273 & 1.464 & & \\
\hline \multirow{2}{*}{$\mathrm{B}_{2}$} & RS & 4.075 & 1.597 & \multirow{2}{*}{-0.370} & \multirow{2}{*}{.970} & \multirow{2}{*}{$\mathrm{B}_{2}$} & RS & 4.028 & 1.424 & \multirow{2}{*}{-.033} & \multirow{2}{*}{.974} & \multirow{2}{*}{$\mathrm{B}_{2}$} & $\mathrm{RS}$ & 3.998 & 1.332 & \multirow{2}{*}{-4.290} & \multirow{2}{*}{.671} \\
\hline & SS & 4.098 & 1.812 & & & & SS & 4.046 & 1.582 & & & & SS & 4.224 & 1.547 & & \\
\hline \multirow{2}{*}{$\mathrm{B}_{3}$} & RS & 3.313 & 1.461 & \multirow{2}{*}{-2.654} & \multirow{2}{*}{.013} & \multirow{2}{*}{$\mathrm{B}_{3}$} & $\mathrm{RS}$ & 3.390 & 1.614 & \multirow{2}{*}{-2.485} & \multirow{2}{*}{.019} & \multirow{2}{*}{$\mathrm{B}_{3}$} & RS & 3.311 & 1.542 & \multirow{2}{*}{-2.488} & \multirow{2}{*}{.019} \\
\hline & SS & 5.373 & 2.628 & & & & SS & 4.946 & 1.811 & & & & SS & 4.998 & 2.127 & & \\
\hline \multirow{2}{*}{$\mathrm{B}_{4}$} & $\mathrm{RS}$ & 6.481 & 4.502 & \multirow{2}{*}{-3.489} & \multirow{2}{*}{.002} & \multirow{2}{*}{$\mathrm{B}_{4}$} & RS & 6.927 & 4.667 & \multirow{2}{*}{-3.282} & \multirow{2}{*}{.003} & \multirow{2}{*}{$\mathrm{B}_{4}$} & RS & 6.183 & 3.704 & -3690 & .001 \\
\hline & SS & 15.095 & 8.436 & & & & SS & 12.790 & 5.106 & & & & SS & 12.981 & 6.098 & & \\
\hline
\end{tabular}

TABLE 5: Analysis of male brain wave differences between resumed stage and stimulated stage in phases of $f_{1}, f_{2}$, and $f_{3}$ by $t$-test.

\begin{tabular}{|c|c|c|c|c|c|c|c|c|c|c|c|c|c|c|c|c|c|}
\hline & 1 & M & SD & $t$ & $P$ & \multicolumn{2}{|c|}{$f_{2}$} & $\mathrm{M}$ & SD & $t$ & $P$ & \multicolumn{2}{|c|}{$f_{3}$} & M & SD & $t$ & $P$ \\
\hline \multirow{2}{*}{$\mathrm{B}_{1}$} & $\mathrm{RS}$ & 5.155 & 2.538 & \multirow{2}{*}{1.372} & \multirow{2}{*}{.181} & \multirow{2}{*}{$\mathrm{B}_{1}$} & RS & 5.296 & 2.806 & \multirow{2}{*}{1.685} & \multirow{2}{*}{.103} & \multirow{2}{*}{$\mathrm{B}_{1}$} & RS & 4.750 & 3.333 & \multirow{2}{*}{1.202} & \multirow{2}{*}{.242} \\
\hline & SS & 4.055 & 1.791 & & & & SS & 3.844 & 1.809 & & & & SS & 3.549 & 1.970 & & \\
\hline \multirow{2}{*}{$\mathrm{B}_{2}$} & $\mathrm{RS}$ & 3.737 & 1.115 & \multirow{2}{*}{-.532} & \multirow{2}{*}{.599} & \multirow{2}{*}{$\mathrm{B}_{2}$} & RS & 4.258 & 1.227 & \multirow{2}{*}{.840} & \multirow{2}{*}{.408} & \multirow{2}{*}{$\mathrm{B}_{2}$} & RS & 3.791 & 1.618 & \multirow{2}{*}{-.208} & \multirow{2}{*}{.837} \\
\hline & SS & 3.965 & 1.236 & & & & SS & 3.873 & 1.280 & & & & SS & 3.907 & 1.430 & & \\
\hline \multirow{2}{*}{$\mathrm{B}_{3}$} & $\mathrm{RS}$ & 3.735 & 1.412 & \multirow{2}{*}{-1.816} & \multirow{2}{*}{.084} & \multirow{2}{*}{$\mathrm{B}_{3}$} & RS & 4.001 & 1.673 & \multirow{2}{*}{-1.172} & \multirow{2}{*}{.251} & \multirow{2}{*}{$\mathrm{B}_{3}$} & RS & 3.271 & 1.801 & \multirow{2}{*}{-1.440} & \multirow{2}{*}{.161} \\
\hline & SS & 5.227 & 2.851 & & & & SS & 4.908 & 2.485 & & & & SS & 4.350 & 2.275 & & \\
\hline \multirow{2}{*}{$\mathrm{B}_{4}$} & RS & 6.238 & 2.267 & \multirow{2}{*}{-3.019} & \multirow{2}{*}{.008} & \multirow{2}{*}{$\mathrm{B}_{4}$} & RS & 7.822 & 3.853 & \multirow{2}{*}{-2.184} & \multirow{2}{*}{.040} & \multirow{2}{*}{$\mathrm{B}_{4}$} & RS & 6.237 & 3.823 & & .053 \\
\hline & SS & 13.133 & 8.550 & & & & SS & 12.579 & 7.502 & & & & SS & 10.180 & 6.532 & & נסט. \\
\hline
\end{tabular}

quiet in the evaluating room in order not to be disturbed. A total of 30 participants are divided into 3 groups by age in this experiment. The age of the first group (Age 1) is 18 to 29, the second group (Age 2) is 30 to 49, and the third group (Age 3) is 50 to 65 . Each group consists of 10 participants; male and female are in the same quantity.

\section{Results and Discussions}

The EEG instrument was applied to measure the brain wave's strength at different flashing frequencies and to evaluate the biological state of the participants at resumed stage and stimulated stage. The measuring data obtained will be further analyzed and compared based on different stimulation condition, participant's age, and gender. Therefore, all the participants' brain waves need to be stabilized at resumed stage of phases of $f_{1}, f_{2}$, and $f_{3}$ for the comparison of stimulated stage. The participants' brain waves at resumed stage of phases of $f_{1}, f_{2}$, and $f_{3}$ for sample 1 , sample 2 , and sample 3 were shown in Table 1 . The $P$ values of the differences among all the phases of $f_{1}, f_{2}$, and $f_{3}$ for all samples and all brain waves $\left(\mathrm{B}_{1}, \mathrm{~B}_{2}, \mathrm{~B}_{3}\right.$, and $\left.\mathrm{B}_{4}\right)$ are all larger than 0.05; that is, there are no significant differences of their brain wave activities in all phases according to ANOVA test. We can confirm that the brain wave after 3 minutes rest of closing eyes can be stabilized and be able to resume the original status before starting the measurement of stimulated stage.

(1) Analysis of Brain Wave at Different Stimulated Stage. The brain wave differences between the resumed stage (RS) and the stimulated stage (SS) in phases of $f_{1}, f_{2}$, and $f_{3}$ were analyzed according to the $t$-test. The results were listed in Table 2 and described as follows. For all the phases of $f_{1}$, $f_{2}$, and $f_{3}$, Alpha waves $\left(B_{1}\right)$ are decreased significantly and transferred into Theta wave $\left(B_{3}\right)$ and Delta wave $\left(B_{4}\right)$ standing for the slights sleeping status. The less the brain wave's frequency (e.g., $B_{4}<B_{3}$ ), the more significant increasing is the brain wave's strength (e.g., $B_{4}>B_{3}$ ); that is, the reaction of the brain wave can be changed when the participants was stimulated by the light out of the optical fiber in biofeedback fabric, as well as the brain wave strength is more obviously and easily enhanced for the lower frequency of brain wave. The results demonstrated that the brain wave can be changed and reached to a status of slight sleeping $\left(B_{4}\right.$ ands $\left.B_{3}\right)$ from relaxation status $\left(B_{1}\right)$. As to the high frequency of the Beta wave $\left(B_{2}\right)$, standing for the exciting and sobering status, there is no significant difference between the resumed stage and the stimulated stage because the participants' original status is relaxant. The further analyses of brain waves at the stimulated stage in different flashing frequencies were listed in Table 3. For all the brain waves of $B_{1}, B_{2}, B_{3}$, and $B_{4}$, there are no significant differences among the 3 different flashing frequencies according to ANOVA test. The results showed that the biofeedback fabrics in conditions of 3 kinds of flashing frequencies are all effective.

(2) Analysis of Brain Wave for Male and Female at Different Stimulated Stage. The analyses of brain wave strength for female and male at different flashing frequencies were listed in Tables 4 and 5. For female brain waves at different flashing frequencies, their Alpha waves showed slight decreasing and their Theta wave and Delta wave showed significant 
TABLE 6: Analysis of brain waves differences between resumed stage and stimulated stage for Age 1 group in phases of $f_{1}, f_{2}$, and $f_{3}$ by $t$-test.

\begin{tabular}{|c|c|c|c|c|c|c|c|c|c|c|c|c|c|c|c|c|c|}
\hline J & $f_{1}$ & $\mathrm{M}$ & SD & $t$ & $P$ & & $f_{2}$ & $\mathrm{M}$ & $\mathrm{SD}$ & $t$ & $P$ & & & $\mathrm{M}$ & $\mathrm{SD}$ & $t$ & $P$ \\
\hline \multirow{2}{*}{$\mathrm{B}_{1}$} & RS & 5.255 & 2.035 & \multirow{2}{*}{1.876} & \multirow{2}{*}{.078} & \multirow{2}{*}{$\mathrm{B}_{1}$} & RS & 5.023 & 2.371 & \multirow{2}{*}{1.886} & \multirow{2}{*}{.076} & \multirow{2}{*}{$\mathrm{B}_{1}$} & RS & 4.914 & 2.610 & \multirow{2}{*}{1.621} & \multirow{2}{*}{.122} \\
\hline & SS & 3.616 & 1.342 & & & & SS & 3.430 & 1.230 & & & & SS & 3.364 & 1.525 & & \\
\hline \multirow{2}{*}{$\mathrm{B}_{2}$} & RS & 3.897 & 1.441 & \multirow{2}{*}{.065} & \multirow{2}{*}{.949} & \multirow{2}{*}{$\mathrm{B}_{2}$} & RS & 3.735 & 1.279 & \multirow{2}{*}{-.215} & \multirow{2}{*}{.832} & \multirow{2}{*}{$\mathrm{B}_{2}$} & RS & 3.506 & 1.244 & \multirow{2}{*}{-.966} & \multirow{2}{*}{.347} \\
\hline & SS & 3.851 & 1.719 & & & & SS & 3.878 & 1.671 & & & & SS & 4.113 & 1.550 & & \\
\hline \multirow{2}{*}{$\mathrm{B}_{3}$} & RS & 3.752 & 1.474 & \multirow{2}{*}{-1.187} & \multirow{2}{*}{.251} & \multirow{2}{*}{$\mathrm{B}_{3}$} & RS & 3.690 & 1.509 & \multirow{2}{*}{-.786} & \multirow{2}{*}{.442} & \multirow{2}{*}{$\mathrm{B}_{3}$} & RS & 3.585 & 1.677 & \multirow{2}{*}{-.810} & \multirow{2}{*}{.428} \\
\hline & SS & 4.798 & 2.365 & & & & SS & 4.259 & 1.723 & & & & SS & 4.272 & 2.092 & & \\
\hline \multirow{2}{*}{$\mathrm{B}_{4}$} & RS & 8.142 & 4.585 & \multirow{2}{*}{-1.641} & \multirow{2}{*}{.118} & \multirow{2}{*}{$\mathrm{B}_{4}$} & RS & 8.795 & 4.816 & \multirow{2}{*}{-1.011} & \multirow{2}{*}{.326} & \multirow{2}{*}{$\mathrm{B}_{4}$} & RS & 7.349 & 4.204 & \multirow{2}{*}{-1.463} & \multirow{2}{*}{.161} \\
\hline & SS & 13.215 & 8.631 & & & & SS & 11.002 & 4.950 & & & & SS & 10.763 & 6.062 & & \\
\hline
\end{tabular}

TABLE 7: Analysis of brain waves differences between resumed stage and stimulated stage for Age 2 group in phases of $f_{1}, f_{2}$, and $f_{3}$ by $t$-test.

\begin{tabular}{|c|c|c|c|c|c|c|c|c|c|c|c|c|c|c|c|c|c|}
\hline & $f_{1}$ & $\mathrm{M}$ & SD & $t$ & $P$ & & $f_{2}$ & $\mathrm{M}$ & SD & $t$ & $P$ & & & $\mathrm{M}$ & SD & $t$ & $P$ \\
\hline \multirow{2}{*}{$\mathrm{B}_{1}$} & RS & 4.946 & 2.749 & \multirow{2}{*}{.829} & \multirow{2}{*}{.418} & \multirow{2}{*}{$\mathrm{B}_{1}$} & RS & 5.185 & 3.213 & \multirow{2}{*}{1.139} & \multirow{2}{*}{.269} & \multirow{2}{*}{$\mathrm{B}_{1}$} & RS & 4.975 & 3.178 & \multirow{2}{*}{1.141} & \multirow{2}{*}{.269} \\
\hline & SS & 4.009 & 2.878 & & & & SS & 3.791 & 2.156 & & & & SS & 3.597 & 2.117 & & \\
\hline \multirow{2}{*}{$\mathrm{B}_{2}$} & $\mathrm{RS}$ & 3.597 & 1.340 & \multirow{2}{*}{-.659} & \multirow{2}{*}{.518} & \multirow{2}{*}{$\mathrm{B}_{2}$} & RS & 4.100 & 1.502 & \multirow{2}{*}{.219} & \multirow{2}{*}{.829} & \multirow{2}{*}{$\mathrm{B}_{2}$} & RS & 4.121 & 1.634 & \multirow{2}{*}{.357} & \multirow{2}{*}{.725} \\
\hline & SS & 4.020 & 1.523 & & & & SS & 3.949 & 1.587 & & & & SS & 3.861 & 1.623 & & \\
\hline \multirow{2}{*}{$\mathrm{B}_{3}$} & $\mathrm{RS}$ & 3.424 & 1.668 & \multirow{2}{*}{-2.434} & \multirow{2}{*}{.026} & \multirow{2}{*}{$\mathrm{B}_{3}$} & RS & 3.484 & 1.798 & \multirow{2}{*}{-2.356} & \multirow{2}{*}{.030} & \multirow{2}{*}{$\mathrm{B}_{3}$} & RS & 3.324 & 1.643 & \multirow{2}{*}{-2.319} & \multirow{2}{*}{.032} \\
\hline & SS & 6.280 & 3.315 & & & & SS & 5.772 & 2.489 & & & & SS & 5.448 & 2.386 & & \\
\hline \multirow{2}{*}{$\mathrm{B}_{4}$} & $\mathrm{RS}$ & 5.703 & 3.068 & \multirow{2}{*}{-3.678} & \multirow{2}{*}{.006} & \multirow{2}{*}{$\mathrm{B}_{4}$} & RS & 6.777 & 3.960 & \multirow{2}{*}{-3.192} & \multirow{2}{*}{.005} & \multirow{2}{*}{$\mathrm{B}_{4}$} & RS & 6.595 & 3.466 & \multirow{2}{*}{-3.128} & \multirow{2}{*}{.006} \\
\hline & SS & 16.160 & 9.302 & & & & SS & 15.007 & 7.128 & & & & SS & 13.945 & 6.574 & & \\
\hline
\end{tabular}

TABLE 8: Analysis of brain waves differences between resumed stage and stimulated stage for Age 3 group in phases of $f_{1}, f_{2}$, and $f_{3}$ by $t$-test.

\begin{tabular}{|c|c|c|c|c|c|c|c|c|c|c|c|c|c|c|c|c|c|}
\hline. & $f_{1}$ & $\mathrm{M}$ & SD & $t$ & $P$ & & $c_{2}$ & $\mathrm{M}$ & SD & $t$ & $P$ & & & $\mathrm{M}$ & SD & $t$ & $P$ \\
\hline \multirow{2}{*}{$\mathrm{B}_{1}$} & & 4.793 & 1.974 & \multirow{2}{*}{1.949} & \multirow{2}{*}{.067} & \multirow{2}{*}{$\mathrm{B}_{1}$} & RS & 5.373 & 2.840 & \multirow{2}{*}{1.978} & \multirow{2}{*}{.063} & \multirow{2}{*}{$\mathrm{B}_{1}$} & RS & 4.395 & 3.272 & \multirow{2}{*}{.976} & \multirow{2}{*}{.342} \\
\hline & SS & 3.437 & .972 & & & & SS & 3.485 & 1.023 & & & & SS & 3.271 & 1.603 & & \\
\hline \multirow{2}{*}{$\mathrm{B}_{2}$} & RS & 4.223 & 1.382 & \multirow{2}{*}{-.002} & \multirow{2}{*}{.999} & \multirow{2}{*}{$\mathrm{B}_{2}$} & RS & 4.594 & 1.112 & \multirow{2}{*}{1.113} & \multirow{2}{*}{.281} & \multirow{2}{*}{$\mathrm{B}_{2}$} & RS & 4.057 & 1.547 & \multirow{2}{*}{-.254} & \multirow{2}{*}{.802} \\
\hline & SS & 4.224 & 1.464 & & & & SS & 4.052 & 1.066 & & & & SS & 4.223 & 1.370 & & \\
\hline \multirow{2}{*}{$\mathrm{B}_{3}$} & RS & 3.396 & 1.237 & \multirow{2}{*}{-1.735} & \multirow{2}{*}{.100} & \multirow{2}{*}{$\mathrm{B}_{3}$} & RS & 3.913 & 1.761 & \multirow{2}{*}{-.978} & \multirow{2}{*}{.341} & \multirow{2}{*}{$\mathrm{B}_{3}$} & RS & 2.964 & 1.738 & \multirow{2}{*}{-1.556} & \multirow{2}{*}{.137} \\
\hline & SS & 4.821 & 2.284 & & & & SS & 4.750 & 2.054 & & & & SS & 4.302 & 2.091 & & \\
\hline \multirow{2}{*}{$\mathrm{B}_{4}$} & RS & 5.234 & 1.929 & \multirow{2}{*}{-3.072} & \multirow{2}{*}{.012} & \multirow{2}{*}{$\mathrm{B}_{4}$} & RS & 6.552 & 3.922 & \multirow{2}{*}{-2.269} & \multirow{2}{*}{.036} & \multirow{2}{*}{$\mathrm{B}_{4}$} & RS & 4.685 & 3.195 & \multirow{2}{*}{-2.359} & \multirow{2}{*}{.034} \\
\hline & SS & 12.961 & 7.717 & & & & SS & 12.044 & 6.575 & & & & SS & 10.033 & 6.417 & & \\
\hline
\end{tabular}

TABLE 9: Analysis of sleeping scale differences between $f_{0}$ and after stimulated in phases of $f_{1}, f_{2}$, and $f_{3}$ by $t$-test for sample 1 , sample 2 , and sample 3.

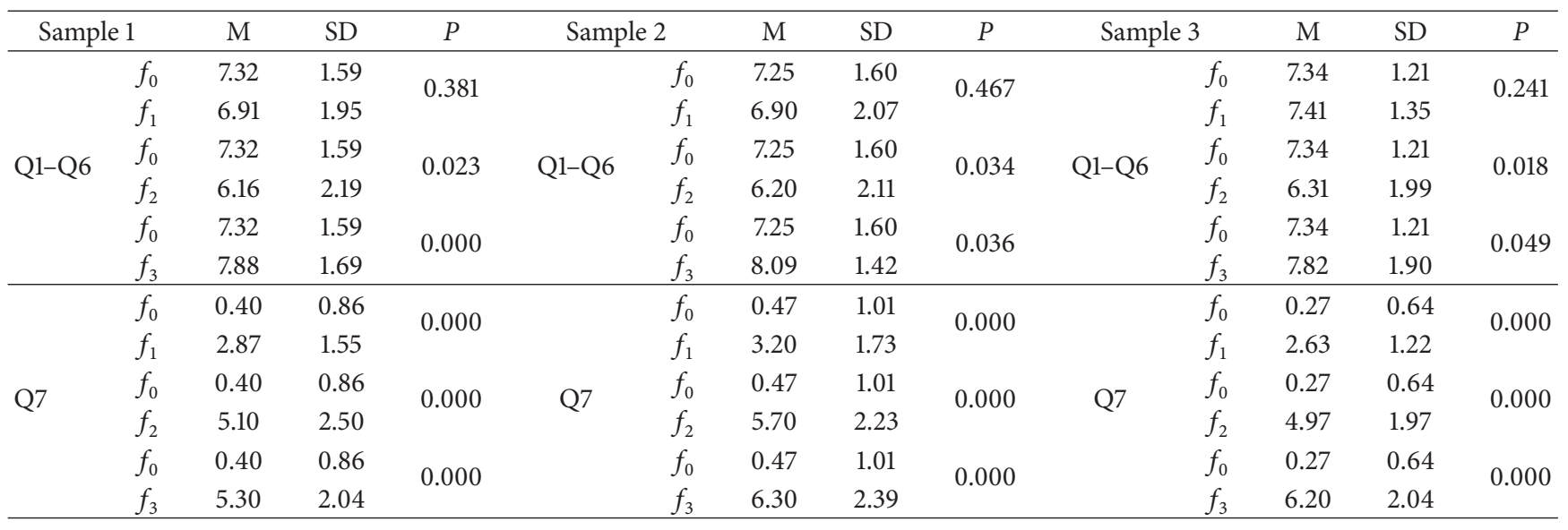


TABLE 10: Analysis of female sleeping scale differences between $f_{0}$ and after stimulated in phases of $f_{1}, f_{2}$, and $f_{3}$ by $t$-test for sample 1 , sample 2, and sample 3 .

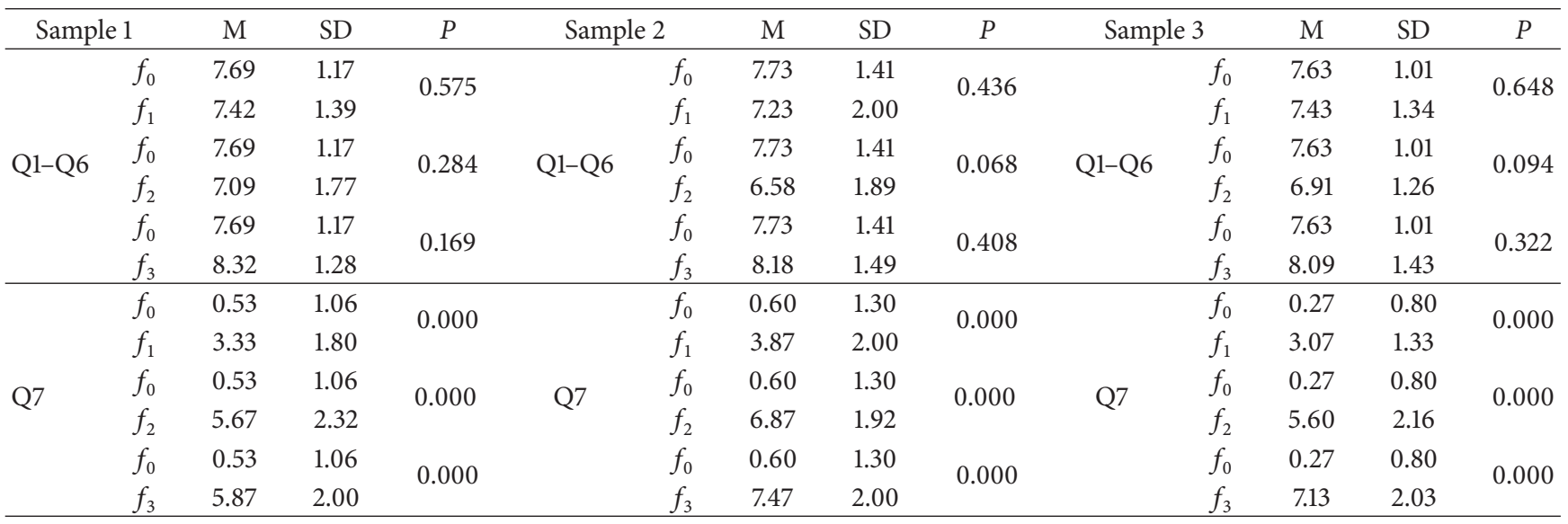

increasing. This result demonstrated that the biofeedback fabrics in conditions of different flashing frequencies are all effective for female. As to male, the result was the same with female. The biofeedback fabrics in conditions of 3 kinds of flashing frequencies are all effective to male. Comparing female with male, the effect in enhancing sleeping sense for female is more significant than it for male because the changes of Alpha wave decreasing and Theta/Delta wave increasing for female are more significant than it for male; that is, the female's brain wave is easier to be changed than it for male's brain wave.

(3) Analysis of Brain Wave for Age 1, Age 2, and Age 3 at Different Stimulated Stage. The analyses of brain waves strength for groups of Age 1, Age 2, and Age 3 at different flashing frequencies were listed in Tables 6, 7, and 8. For the Age 1 (18 to 29) group, the Alpha waves were decreased and the Theta/Delta waves were increased, but all of them were not significant. For the Age 2 (30 to 49) group, the Alpha waves were decreased, however they were not significant, but the Theta and Delta waves were significantly increased. For the Age 3 (50 to 65) group, the Alpha waves were decreased and the Theta waves were increased; however they were not significant, but the Delta waves were increased and reached a significant level. According to the aforementioned results, the effect in enhancing sleeping sense for Age 2 group is the best among all the groups of Age, and Age 1 group ranks behind Age 3 group. Maybe the stress of the Age 2 group is the strongest among all the groups of Age and the stress of the Age 3 group is stronger than Age 1 group. Therefore, we can infer from the results that the stronger the participant's stress is, the more obvious the effect in enhancing sleeping sense is.

(4) Analysis of Sleeping Scale at Different Stimulated Stages for Different Samples. The sleeping scale was applied to investigate the enhancement effect of sleeping sense for the participants at different flashing frequencies for 3 samples. The evaluating data, that is, the sleeping scale score, obtained were further analyzed based on different sample stimulation, participant's age, and gender. The results were elaborated as below. The score differences of sleeping scale between $f_{0}$ after the resumed stage (RS) and after the stimulated stage (SS) in phases of $f_{1}, f_{2}$, and $f_{3}$ for sample 1 , sample 2 , and sample 3 were analyzed according to the $t$-test. The results were listed in Table 9. For all the samples in phases of $f_{1}, f_{2}$, and $f_{3}$, the differences of Q7 standing for sleeping sense between $\left(f_{0}\right)$ after $\mathrm{RS}$ and $\left(f_{1}, f_{2}, f_{3}\right)$ after SS were extremely significantly increased. Their $P$ values were all reaching 0.000. The differences of Q1-Q6 standing for relaxed feel for $f_{3}(10 \mathrm{~Hz})$ were increased significantly. Their $P$ values were less than 0.05. Adversely, the differences of Q1Q6 for $f_{2}(5 \mathrm{~Hz})$ were decreased significantly. Besides, the difference was not significant while comparing $f_{0}$ with $f_{1}$ $(0 \mathrm{~Hz})$. The results demonstrated that the sleeping sense of the participants can be enhanced when their visual system were stimulated by all samples in frequencies of $f_{1}, f_{2}$, and $f_{3}$. However, the relaxed feel of the participants can be enhanced while stimulating only in frequency of $f_{3}$ for all samples.

(5) Analysis of Sleeping Scale for Male And Female at Different Stimulated Stages for Different Samples. The score differences of sleeping scale for male and female between $f_{0}$ after the resumed stage (RS) and after the stimulated stage (SS) in phases of $f_{1}, f_{2}$, and $f_{3}$ for sample 1 , sample 2 , and sample 3 were analyzed and the results were listed in Tables 10 and 11. For all the samples in phases of $f_{1}, f_{2}$, and $f_{3}$, the differences for male and female of Q7 standing for sleeping sense between $f_{0}$ (after RS) and $f_{1}, f_{2}$, and $f_{3}$ (after SS) were extremely significantly increased. Their $P$ values were all reaching 0.000 . Adversely, the differences of Q1-Q6 for male and female were not significant while comparing $f_{0}$ with $f_{1}, f_{2}$, and $f_{3}$. The results demonstrated that the sleeping sense of the participants for male and female can be enhanced extremely significantly when their visual system were stimulated for all samples in the frequencies of $f_{1}, f_{2}$, and $f_{3}$. However, the relaxed feel of the participants cannot be enhanced significantly while stimulating in the frequencies of $f_{1}, f_{2}$, and $f_{3}$ for all samples. Besides, the higher the flashing 
TABLE 11: Analysis of male sleeping scale differences between $f_{0}$ and after stimulated in phases of $f_{1}, f_{2}$, and $f_{3}$ by $t$-test for sample 1 , sample 2 , and sample 3 .

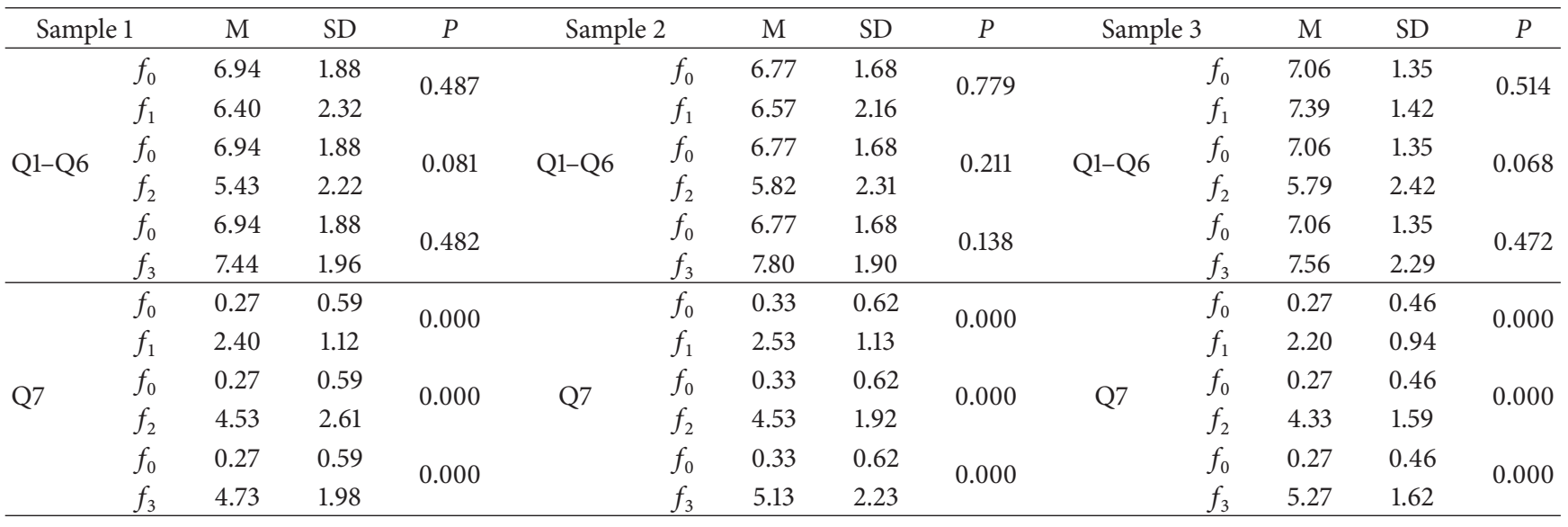

TABLE 12: Analysis of sleeping scale differences between $f_{0}$ and after SS for sample 1 in phases of $f_{1}, f_{2}$, and $f_{3}$ by $t$-test for groups of Age 1 , Age 2, and Age 3.

\begin{tabular}{|c|c|c|c|c|c|c|c|c|c|c|c|c|c|c|}
\hline \multicolumn{2}{|c|}{ Age 1} & \multirow{2}{*}{$\frac{\mathrm{M}}{7.51}$} & \multirow{2}{*}{$\begin{array}{c}\mathrm{SD} \\
1.12\end{array}$} & \multirow{3}{*}{$\begin{array}{c}P \\
0.628\end{array}$} & \multicolumn{2}{|c|}{ Age 2} & \multirow{3}{*}{$\begin{array}{c}\mathrm{M} \\
6.89 \\
6.72\end{array}$} & \multirow{3}{*}{$\begin{array}{c}\text { SD } \\
1.28 \\
1.77\end{array}$} & \multirow{3}{*}{$\begin{array}{c}P \\
0.678\end{array}$} & \multicolumn{2}{|c|}{ Age 3} & \multirow{2}{*}{$\frac{\mathrm{M}}{7.51}$} & \multirow{2}{*}{$\begin{array}{c}\text { SD } \\
1.84\end{array}$} & \multirow{2}{*}{$\begin{array}{c}P \\
0.490\end{array}$} \\
\hline \multirow{6}{*}{ Q1-Q6 } & $f_{0}$ & & & & & $f_{0}$ & & & & & $f_{0}$ & & & \\
\hline & $f_{1}$ & 7.35 & 1.42 & & & $f_{1}$ & & & & & $f_{1}$ & 7.15 & 2.17 & \\
\hline & $f_{0}$ & 7.51 & 1.12 & \multirow{2}{*}{0.009} & \multirow{4}{*}{ Q1-Q6 } & $f_{0}$ & 6.89 & 1.28 & \multirow{2}{*}{0.011} & \multirow{4}{*}{ Q1-Q6 } & $f_{0}$ & 7.51 & 1.84 & \multirow{2}{*}{0.052} \\
\hline & $f_{2}$ & 6.60 & 1.46 & & & $f_{2}$ & 5.62 & 2.29 & & & $f_{2}$ & 6.45 & 2.29 & \\
\hline & $f_{0}$ & 7.51 & 1.12 & \multirow{2}{*}{0.299} & & $f_{0}$ & 6.89 & 1.28 & \multirow{2}{*}{0.136} & & $f_{0}$ & 7.51 & 1.84 & \multirow{2}{*}{0.045} \\
\hline & $f_{3}$ & 7.81 & 1.10 & & & $f_{3}$ & 7.58 & 2.14 & & & $f_{3}$ & 8.41 & 1.53 & \\
\hline \multirow{6}{*}{ Q7 } & $f_{0}$ & 0.30 & 0.47 & \multirow{2}{*}{0.000} & \multirow{6}{*}{ Q7 } & $f_{0}$ & 0.70 & 1.29 & \multirow{2}{*}{0.000} & \multirow{6}{*}{ Q7 } & $f_{0}$ & 0.13 & 0.35 & \multirow{2}{*}{0.000} \\
\hline & $f_{1}$ & 2.27 & 1.14 & & & $f_{1}$ & 3.97 & 1.71 & & & $f_{1}$ & 2.47 & 1.01 & \\
\hline & $f_{0}$ & 0.30 & 0.47 & \multirow{2}{*}{0.000} & & $f_{0}$ & 0.70 & 1.29 & \multirow{2}{*}{0.000} & & $f_{0}$ & 0.13 & 0.35 & 0.000 \\
\hline & $f_{2}$ & 5.03 & 1.97 & & & $f_{2}$ & 6.07 & 2.56 & & & $f_{2}$ & 4.67 & 1.97 & \\
\hline & $f_{0}$ & 0.30 & 0.47 & \multirow{2}{*}{0.000} & & $f_{0}$ & 0.70 & 1.29 & \multirow{2}{*}{0.000} & & $f_{0}$ & 0.13 & 0.35 & \multirow{2}{*}{0.000} \\
\hline & $f_{3}$ & 5.40 & 1.40 & & & $f_{3}$ & 6.83 & 2.60 & & & $f_{3}$ & 5.57 & 2.16 & \\
\hline
\end{tabular}

frequency, the better the effect in enhancing sleeping sense for both genders of participants. The enhancement effect in sleeping sense for female is better than it for male.

(6) Analysis of Sleeping Scale for Age Groups at Different Stimulated Stages. The score differences of sleeping scale between $f_{0}$ (after RS) and $f_{1}, f_{2}$, and $f_{3}$ (after SS) for 3 groups of Age 1 , Age 2, and Age 3 were analyzed and their results were listed in Table 12. For the sample 1 in phases of $f_{1}, f_{2}$, and $f_{3}$, the differences of Q7 standing for sleeping sense between $f_{0}$ (after RS) and $f_{1}, f_{2}$, and $f_{3}$ (after SS) were extremely significantly increased. Their $P$ values were all reaching 0.000 . Adversely, the differences for all Age groups of Q1-Q6 were no significant differences while comparing $f_{0}$ with $f_{1}, f_{2}$, and $f_{3}$. The results demonstrated that the sleeping sense of the participants for all Age groups can be enhanced extremely when their visual system were stimulated by sample 1 in frequencies of $f_{1}, f_{2}$, and $f_{3}$. However, the relaxed feel of the participants of all Age groups cannot be enhanced significantly while stimulating in frequencies of $f_{1}, f_{2}$, and $f_{3}$ for sample 1 . Besides, the higher the flashing frequency, the better the enhancing sleeping sense for 3 Age groups of participants. The effect of enhancing sleeping sense for Age 2 group (30 49) is the best among 3 Age groups. Maybe the stress of Age 2 group is the strongest among all the groups of Age. Therefore, we can infer from the results that the stronger the participant's stress is, the more obvious the effect in enhancing sleeping sense is, and it is same with the results of above Table 6 to Table 8 .

\section{Conclusion}

We designed a unique biofeedback fabric including background layer and pattern layer, 3 kinds of wavelengths of sine waves, and 3 kinds of flashing frequencies based on the biofeedback principle for enhancing sleeping sense and evaluated its performance according to the brain wave measured with EEG and the sleeping scale was developed by ourselves. The results can be summarized as follows.

(1) For all the phases of $f_{1}, f_{2}$, and $f_{3}$, Alpha waves $\left(\mathrm{B}_{1}\right)$ are decreased significantly and transferred into Theta wave $\left(B_{3}\right)$ and Delta wave $\left(B_{4}\right)$; that is, the biofeedback fabrics in conditions of 3 kinds of flashing frequencies 
for all samples are all effective in enhancing sleeping sense.

(2) The effect in enhancing sleeping sense for female is more significant than it for male.

(3) The effect in enhancing sleeping sense for Age 2 group (30-49) is the best among all Age groups.

(4) The stronger the participant's stress is, the more obvious the effect in enhancing sleeping sense is.

\section{Conflict of Interests}

The authors declare that there is no conflict of interests regarding the publication of this paper.

\section{Acknowledgments}

The authors would like to take this opportunity to thank to Industrial Development Bureau, Ministry of Economic Affairs (MOEA) for the financial support. They also would like to thank the authority of Shu-Te University for providing them with a good environment and facilities to complete this project. Finally, they would like to express their heartfelt thanks to all of the participants for their help in this study.

\section{References}

[1] L. Engel and L. B. Andersen, "Effects of body-mind training and relaxation stretching on persons with chronic toxic encephalopathy," Patient Education and Counseling, vol. 39, no. 2-3, pp. 155-161, 2000.

[2] G. D. Solomon, "Slow wave photic stimulation in the treatment of headache-a preliminary report," Headache, vol. 25, no. 8, pp. 444-446, 1985.

[3] T. Mulholland, "Human EEG, behavioral stillness and biofeedback," International Journal of Psychophysiology, vol. 19, no. 3, pp. 263-279, 1995.

[4] S. H. Spence, L. Sharpe, T. Newton-John, and D. Champion, "Effect of EMG biofeedback compared to applied relaxation training with chronic, upper extremity cumulative trauma disorders," Pain, vol. 63, no. 2, pp. 199-206, 1995.

[5] P. Williams and M. West, "EEG responses to photic stumulation in persons experienced at meditation," Electroencephalography and Clinical Neurophysiology, vol. 39, no. 5, pp. 519-522, 1975.

[6] J. S. Bell, "The use of EEG theta biofeedback in the treatment of a patient with sleep-onset insomnia," Biofeedback and SelfRegulation, vol. 4, no. 3, pp. 229-236, 1979.

[7] C. H. Bastien, M. LeBlanc, J. Carrier, and C. M. Morin, "Sleep EEG power spectra, insomnia, and chronic use of benzodiazepines," Sleep, vol. 26, no. 3, pp. 313-317, 2003. 

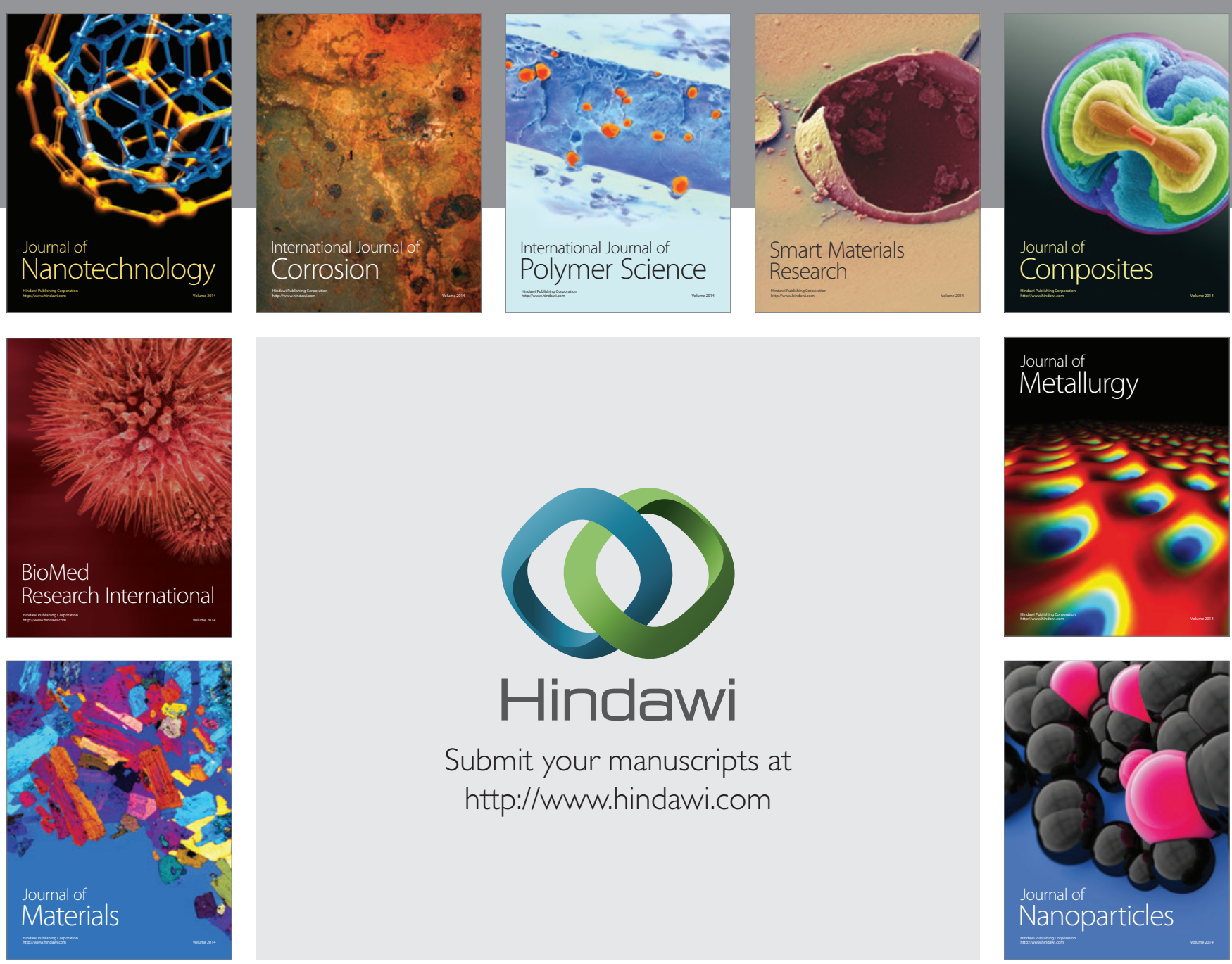

Submit your manuscripts at http://www.hindawi.com
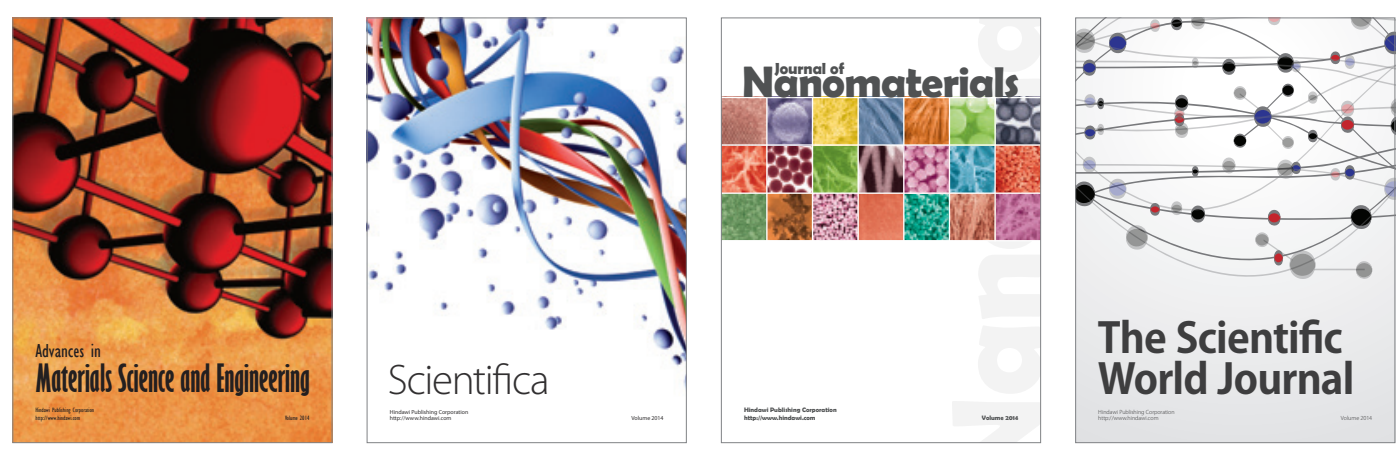

\section{The Scientific World Journal}
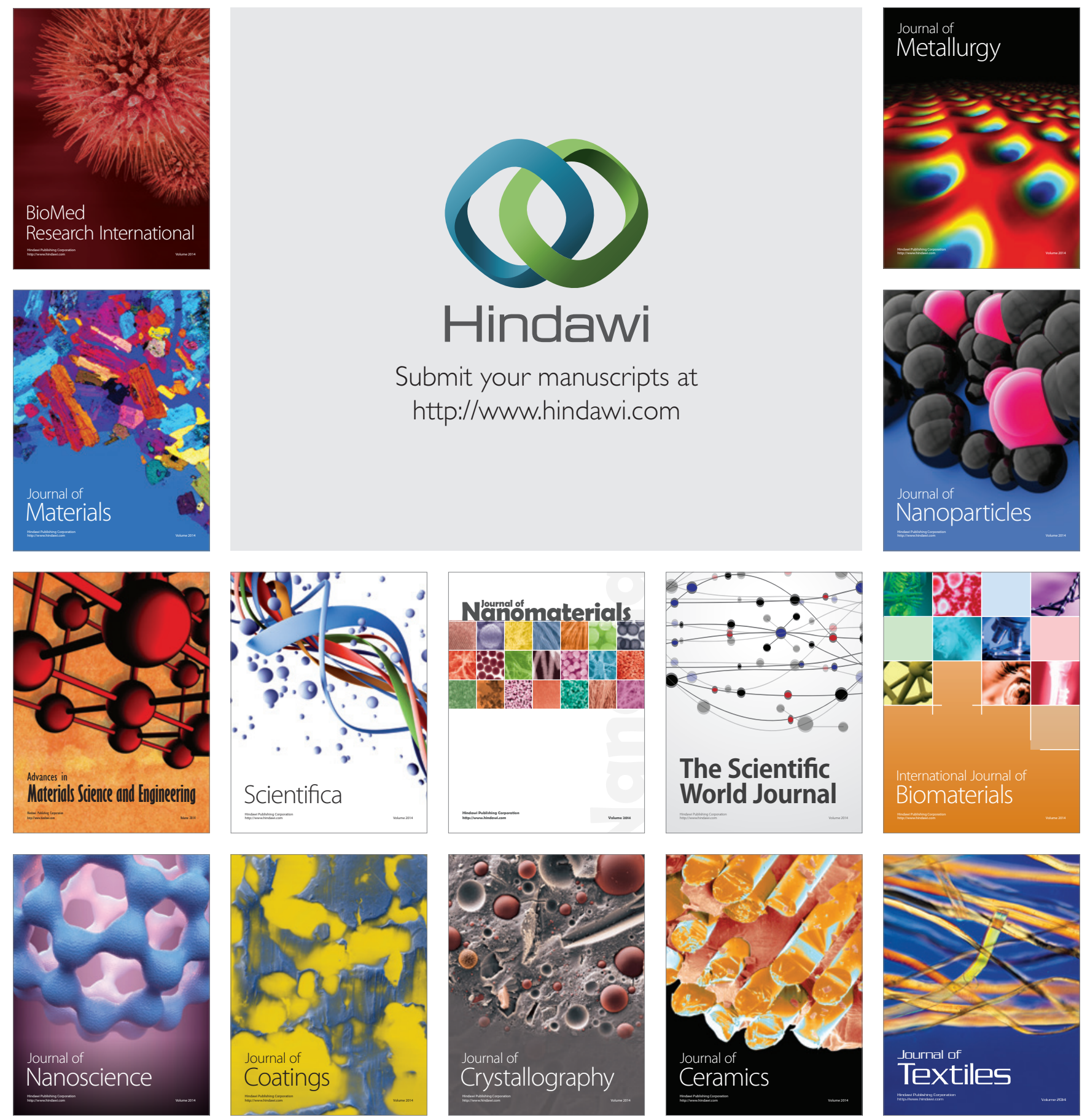